\title{
Cinema e poesia: aproximações à obra de António Reis
}

\author{
Alexandra João Ramos Correia Martins \\ FCSH-Universidade Nova de Lisboa
}

Resumo: 0 presente artigo visa traçar aproximações entre a obra poética de António Reis e a sua obra cinematográfica, realizada em conjunto com Margarida Cordeiro. Tais aproximações serão de ordem formal, tendo em consideração os procedimentos da montagem cinematográfica e os recursos expressivos literários, bem como de ordem temática. 0 que há de poético nos filmes de Reis e Cordeiro? O que há de cinematográfico - ou deveremos dizer, cinemático? - nos poemas de António Reis? Tendo como principal ponto de partida as noções de cinema de poesia (Pier Paolo Pasolini) e cinema da poesia (Rosa Maria Martelo), tentar-se-á aqui aproximar a criação de uma atmosfera (José Gil) e de um estilo comuns às produções estéticas de António Reis, em suma, uma forma de vida (Giorgio Agamben)?

Palavras-chave: António Reis, cinema, poesia, forma-de-vida

\begin{abstract}
The present article aims to map relations between the poetical work by António Reis and his cinematographic work, directed alongside with Margarida Cordeiro. Such relations will be both formal, considering the procedures of film editing and the literary resources, as well as thematic. What's poetic in Reis and Cordeiro's films? What's cinematographic - or shall we say cinematic? - in António Reis' poems? Taking as starting point the notions of cinema of poetry (Pier Paolo Pasolini) and cinema from poetry (Rosa Maria Martelo), we will try to approach the creation of an atmosphere (José Gil) and a common style to the aesthetic productions by António Reis, briefly, a way-of-life (Giorgio Agamben)?
\end{abstract}

Keywords: António Reis, cinema, poetry, way-of-life 


\section{Abertura}

Toujours, la poésie.

Serge Daney

\section{No início, eram os poemas}

Antes de se tornar realizador, António Reis dedicou-se sobretudo à escrita intensiva de poemas e ainda à tradução, nomeadamente de uma série de 50 haikus, em colaboração com outro cineasta português, Paulo Rocha. Tal relação com a tradição poética oriental é apenas um dos múltiplos pontos de entrada para a intersecção entre a imagem e a palavra na estética reisiana: por um lado, como veremos na análise de algumas passagens, a temática da natureza e a forma depurada; por outro, a dimensão manifestamente imagética da escrita japonesa (de que, aliás, os autores não abdicam na edição bilíngue da editora Moraes). Poder-se-ia inferir uma vontade do poeta se tornar realizador por se deparar com os limites da linguagem escrita devotando-se, pois, à produção de imagens, no entanto, António Reis nunca abandonará a palavra, nem mesmo a literatura; esta será fundamental nos seus filmes enquanto palavra dita, nomeadamente na sua primeira curta-metragem Painéis do Porto (1963) (com César Guerra Leal) que reúne poemas do próprio, de Fernando Pessoa, de Pedro Homem de Mello, entre outros, mas também nos subsequentes, que realizará em colaboração com Margarida Cordeiro, seja através das cantilenas de tradição oral transmontana, seja dos poemas de Rainer Maria Rilke, seja de variações de contos de Franz Kafka. Embora o cinema de António Reis e Margarida Cordeiro se encontre impregnado de literatura ("filme de poeta, mas também de geólogos, de antropólogos, de sociólogos" (Daney 1983), dirá Serge Daney acerca de Ana (1982)), o reconhecimento generalizado de uma certa dimensão poética (ou até mesmo de uma "poesia visual") no cinema de António Reis e Margarida Cordeiro baseia-se sobretudo na libertação da expressão formal das imagens face ao jugo da narrativa tradicional, fazendo prevalecer a intensidade inerente às próprias imagens e à montagem - o seu cromatismo, a sua textura, o ritmo, o corte, a duração, o movimento - convidando o espectador à "contemplação" 
(Araújo 2016). Se Reis se afigura a Eduardo Prado Coelho enquanto poeta materialista, do mesmo modo se nos afigura enquanto cineasta materialista:

a sua poesia [o seu cinema] é toda ela regulada por uma concepção materialista do mundo, que não deixa de estar presente (muitas vezes como ausência de) em qualquer dos seus versos [planos]; [...] descer ao nível primordial da necessidade, descobrir a materialidade primeira de todo o homem, revelá-lo como corpo orgânico da matéria, e, portanto, como auto-insuficiência, como matéria de necessidade e necessidade de matéria. (Prado Coelho 1967)

Trata-se de descobrir a materialidade primeira de toda a imagem, revelá-la como corpo orgânico da matéria, seja a película ou as gravuras rupestres do Vale do Côa. Ora, o que aqui se propõe baseia-se precisamente no movimento inverso, procurar o cinemático na poesia de António Reis, tendo como objectos de estudo os quatro filmes realizados em parceria com Margarida Cordeiro e o livro Poemas Quotidianos. Cinemático e não cinematográfico, pois, tratar-se-ia de algo que pré-existe ao próprio dispositivo e que não se refere necessariamente a este (a sala, a projecção, a luz, a película, etc.). Ainda que António Reis se refira pontualmente, nos seus poemas, a "um filme/ um quadro1" (Reis 2017: 74) simultaneamente universal (um qualquer filme) e pessoal (certamente um filme singular) ${ }^{2}$ ou às "salas vazias" (Reis 2017: 115) - que, com algum esforço, poderíamos imaginar tratarem-se de salas de cinema -, o poeta não se inscreve nessa linhagem de poetas contemporâneos portugueses ${ }^{3}$ para quem o cinema surge como figura ecfrásica central e que, nomeadamente, apontam para uma certa ontologia partilhada entre o cinema e a poesia: “qualquer poema é um filme”, dirá Herberto Helder. Nem se aproxima de Luís Miguel Nava cuja poesia surge a partir de uma rememoração inspirada na experiência do cinema (Martelo 2012: 183). António Reis escreve maioritariamente no presente, quando não no infinitivo (cf. infra impessoalidade): "Amor// Comer/ em silêncio/ não [...]" (Reis 2017: 83). Assim, trata-se aqui de tentar desvelar algumas das "formas de intermedialidade de um certo cinema e de uma certa poesia, que assentam em processos comuns de fazer imagem" (Martelo 2012: 11-12), tendo em consideração que, contrariamente aos exemplos 
supra-citados, no caso de António Reis, o exercício é sempre reversível: o cinema da poesia e a poesia do cinema, o que, desde já, justifica os comentários e as referências aos filmes.

\section{Da materialidade quotidiana}

"Descasco as imagens/ e entrego-as na boca// como quem sabe/ o corpo/ mais importante/ que a roupa" (Reis 2017: 44). Tais versos, do poema 22 da mais recente edição de Poemas Quotidianos, revelam não só o materialismo para que apontava Prado Coelho na poesia reisiana, iminentemente carnal e primordial, como alinham uma relação directa entre as imagens e os sentidos do corpo: saborear as imagens. Para Maria Filomena Molder, tais imagens descascadas poderão ser reencontradas na curta-metragem Jaime (1974), na qual

o poeta [António Reis] reduz, ele retira das imagens a ideologia psiquiátrica, a leitura metapsiquiátrica, retira toda a concepção da sociedade, e fica com uma imagem descascada, um olhar sobre os homens que vivem na $8^{\text {a }}$ Enfermaria - ele descascou as imagens e entregou-as na nossa boca, nós temos de prová-las, saborear a dor, a alegria daqueles homens, o lado maravilhosamente mágico e infantil de vários deles, a pobreza, o frio, o jogo, e depois a relação com a terra, com o rio, com os animais, com o vento. (Molder 2018: 29-30)

Embora Molder se refira especificamente a esta curta-metragem, este será um procedimento comum a todos os seus outros filmes - o vento, o rio, a neve, o gelo, as montanhas, os animais, a pobreza, o frio e as cores frias das brancas serranias transmontanas no Inverno, o calor e as cores quentes das serranias douradas no Verão além-Marão. Mas António Reis descasca todas as imagens e não apenas as que compõem os seus filmes, descasca até mesmo aquelas que precedem à escrita dos seus poemas, lá quando se dá o processo de "eclosão do pensamento vendo-o e ouvindo-o" (Martelo 2012: 23).

O cinematismo, na poesia de Reis, advém sobretudo dessa primazia de uma expressão das sensações - que, por vezes, se aproxima até do sensacionismo puro de Alberto Caeiro. A propósito da relação com o cinema de António Reis, Fernando Martinho aponta 
para um exemplo em que sobrevém sobretudo o primado da visão: "Hei-de entrar nas casas/ também// como o silêncio// A ver os retratos dos mortos/ nas paredes/ um bombeiro um menino// A ver os monogramas bordados nos lençóis// os vestidos virados/ os vestidos tingidos/ os diplomas de honra/ as redomas// E a caderneta de Socorros Mútuos/ e Fúnebres// em atraso" (in Reis 2017: 10).

As imagens da poesia de António Reis são também elas descascadas, no sentido em que lhe é atribuído por Maria Filomena Molder, de tal modo que reencontramos os elementos, as sensações e a forma depurada das imagens de Jaime em alguns dos seus poemas: "Há sempre um rapaz triste/ em frente a um barco// a água é sempre azul/ e sempre fresca// Em que país encontraria/ um emprego e esquecimento// em que país encontraria/ amor e compreensão// em que país/ sentiriam/ a sua vida e a sua morte// Não respondem as gaivotas/ porque voam// Há sempre um rapaz triste/ com lágrimas nos olhos/ em frente a um barco" (Reis 2017: 30). O poema não só convoca a forma-descascada proposta por Molder - desta feita com a predominância da água, do molhado, do azul, da lágrima -, como aponta para outras matérias apresentadas por António Reis nos seus filmes subsequentes, sobretudo em Trás-os-Montes (1976): a emigração, o território, os outros países, para trás dos montes, para lá do rio ou do oceano, num cinema do, dizia Daney (1977), distanciamento, no duplo sentido do termo (por um lado, do exílio, da emigração, e, por outro lado, do distanciamento do olhar), simultaneamente tema e matéria do filme. 0 distanciamento é matéria do filme na medida em que aquilo que sai de campo, o fora-decampo, ainda o constitui. Como afirmava Serge Daney, "há a Espanha que é o off da imagem, o que está para além do olhar [imagem da serra em Trás-os-Montes], e a Alemanha que é o off do som, o que está para aquém da voz [leitura de carta de pai emigrado]... Uma zona de sonho e de angústia separa-os e liga-os: é a isto que se chama um 'plano'” (Daney 1977).

\section{A expressão de um mutismo}

Ora, como afirma Eduardo Prado Coelho, também a poesia de António Reis se faz no limiar entre aquilo que aparece e o que não chega a aparecer, ou seja, "quase não chega a aparecer, a ser, quase se reduz a um murmurar sem voz" - "a vida irredutível” (Prado 
Coelho 1967). Redução da poesia que trata de desmistificar e denunciar a cultura, nesse sentido de Ricœur, em que “a cultura é culpada na medida em que é, directa ou indirectamente, um meio de explorar o trabalho: são aqueles que sabem e que falam bem que ordenam, que empreendem, que correm riscos" (apud Prado Coelho). Espécie de contra-palavra, "a palavra que já não se curva diante dos 'cavalos de parada da História'” (Celan 1996: 45), a poesia de Reis apresenta-se como uma poesia do quotidiano e a partir do quotidiano: são os operários e o trabalho, o domingo e o futebol, os cafés, o chegar a casa, em versos curtos, sem rima, sem pontuação e com (re-)cortes, num ritmo que se "arrasta lentamente" e "sonolento" (Prado Coelho 1967) e as inevitáveis repetições de um dia-a-dia. Reis-ventríloquo numa fala de vozes impessoais já que o "quotidiano é uma acção sem sujeito: vai-se para o trabalho, passeia-se aos domingos" (Prado Coelho 1967).

Se, por um lado, Eduardo Prado Coelho apresenta a obra de António Reis como "uma poesia feita de palavras arrancadas à mudez", de tal modo que o poeta "afronta o risco de ver a sua poesia diluir-se em palavras esboroadas, em silêncio asfixiante, em vazio" (Prado Coelho 1967); por outro lado, Serge Daney aponta para uma surdez do enunciado de cada plano (referindo-se a Trás-os-Montes), que questiona "o estatuto - a qualidade de ser - do que sai do campo (do que exprime e do que expulsa)", e afirma ainda que "tudo o que passa pelas franjas do offé susceptível de se tornar outro" (Daney 1977), numa possibilidade de aberturas. Em ambos os casos, apresenta-se uma tensão latente - uma "luta [...] dolorosa e decisiva" (Prado Coelho 1967); uma "inquietude essencial, uma inquietação" (Daney 1977) - entre o dentro e o fora do plano, do poema.

0 (re-) corte $^{4}$ surge, assim, como figura privilegiada, quer no cinema, quer na poesia de António Reis, já que é através daquele que algo se torna (ou não) visível, algo é ou não excluído, e que, sendo excluído (vulgo em off, fora-de-campo, etc.) também constitui o plano ou o verso. É também este corte que torna possível as elipses (e os silêncios) que nos filmes permitem "lavar os olhos entre cada plano" (Daney 1977), algo que se adensa concomitantemente na obra de Reis e Cordeiro até ao derradeiro filme, Rosa de Areia (1989). 5 Como repara Prado Coelho (1967), "a figura de retórica predominante em toda a poesia de António Reis é o zeugma". Se, por um lado, tal figura retórica implica sempre uma 
elipse, já que se constitui a partir da omissão de uma expressão ou palavra, deixando subentendida a repetição do termo e assegurando a coesão significativa; por outro lado, o termo deriva etimologicamente do grego zeygma, que se referiria a algo que serve para juntar. Ou seja, o zeugma é simultaneamente aquilo que se esvazia e que, fazendo-o, permite uma ligação.

Ora, para Paul Celan, a poesia "testemunha a presença do humano" (Celan 1996: 46), "antecipa-nos" (idem: 52). Ainda no mesmo texto, $O$ Meridiano, Celan defende que há uma forte tendência do poema para o emudecimento, que este se afirma à margem de si próprio e que para "poder subsistir, evoca-se e recupera-se incessantemente, num movimento que vai do seu Já-não ao seu Ainda-e-sempre” (idem: 56). Para o autor, tal ainda-e-sempre só pode ser uma "fala", ou melhor dizendo, "linguagem actualizada, liberta sob o signo de um processo de individuação radical, é certo, mas que ao mesmo tempo permanece consciente dos limites que lhe são traçados pela linguagem, das possibilidades que se lhe abrem na linguagem" (idem). A poesia surge, então, como uma experiência-limite da linguagem e tal fala apenas poderá ser encontrada "na poesia de quem não se esquece de que fala sob o ângulo de incidência da sua existência" (idem). Justamente, para Prado Coelho, António Reis trata, na sua poesia, de "fazer da palavra-que-é-falada uma palavra-que-fale" ao "desemudecer a banalidade dum quotidiano exangue" (Prado Coelho 1967) (e repetimos: "o que em cada poema de António Reis se joga não é apenas a poesia, mas a dignidade e o sentido duma existência" (idem)). Para Celan, o poeta integra o poema na medida em que este seria "linguagem, tornada figura, de um ente singular, e na sua essência mais funda, presença e evidência" (Celan 1996: 56). O poema consistiria, pois, em arrancar a fala à linguagem para o plano da existência. Também em Reis, a experiência da linguagem se rebate para o plano da própria existência, da experiência do real, por isso mesmo o poeta-cineasta se referirá aos seus escritos como "poemas vividos", encarando-os "como fazendo parte da vida, dos seus ritmos, dos seus gestos" (Martinho in Reis 2017: 11). Neste sentido, Fernando Martinho aponta como exemplo o próprio poema que dá título à colectânea: "Poemas quotidianos// como o sol/ como a noite// como a vontade de comer/ e o sono// como as preocupações/ e o amor// e porque saio à rua/ e trabalho/ diariamente" (idem). Ainda de 
acordo com Martinho, tais poemas vividos seriam construídos a partir de um "lirismo do vivido, lirismo da experiência" que implicaria não só o "sentido psicológico e biográfico" mas "todos os processos da consciência (percepção, representação, conhecimento, imaginação)" (Martinho in Reis 2017: 11-12), apresentando simultaneamente o concreto e o abstracto, o realismo e o lirismo, num mesmo plano, algo que se reencontrará na proposta pasoliniana.

\section{Para desfazer (qualquer) linguagem 6}

Os limites da linguagem constituem justamente uma das problemáticas dos estudos realizados por Pasolini em torno da linguística e da semiótica, da poesia e do cinema. 0 autor defende que tanto imagens como palavras se constituem enquanto signos, im-signo e lin-signos, no acto de comunicar7 (nomeadamente, o cinema, para Pasolini), no entanto, "o lin-signo adoptado pelo escritor encontra-se já elaborado por toda uma história gramatical, popular e erudita, enquanto o im-signo do autor cinematográfico foi extraído idealmente no seu próprio instante, e apenas por si próprio [...] ao surdo caos das coisas" (Pasolini 1982: 140). Como nota o autor, embora não haja um dicionário imagético ou uma gramática, as imagens constituem, contudo, um "património comum" (idem); não são meros "objectos brutos", tornam-se signos simbólicos (um gesto, um rosto, um movimento diz-nos sempre qualquer coisa ou várias coisas). Assim, para o autor, se o estilo de um poeta se fundava na pré-gramaticalidade dos signos falados, o estilo de um cineasta-autor fundar-se-ia na prégramaticalidade dos próprios objectos (idem).

Para Pasolini, a maior diferença entre uma obra literária e uma obra cinematográfica é que "a instituição linguística, ou gramatical, do autor cinematográfico é formada por imagens e as imagens são sempre concretas, nunca abstractas [...]. Pode ser parábola, mas nunca expressão conceptual directa" (idem: 141), advindo daí a sua violência expressiva e a sua qualidade poética, artística - o cinema de poesia. Nos termos do autor, a "língua técnica da poesia" irrompe no cinema através da instauração de uma subjectiva indirecta livre, o que corresponderia ao discurso indirecto livre no plano literário, um agenciamento que atravessa o autor, a personagem e o ambiente e desfaz o sujeito uno da enunciação na 
criação de uma atmosfera ${ }^{8}$ em que se esbatem as fronteiras entre visão exterior (objectiva, câmara) e visão interior (subjectiva, personagem). Como reparam Deleuze e Guattari, eis o valor exemplar do discurso indirecto livre: "não há contornos distintivos, nítidos, [...] mas um agenciamento colectivo que vai determinar como sua consequência os processos relativos de subjectivação, as atribuições de individualidade e as suas distribuições móveis no discurso" (Deleuze \& Guattari 2007: 113). De tal modo móvel que, adiante, os autores afirmam que o discurso indirecto livre poderia assumir também a forma de um discurso directo: "o meu discurso directo é ainda o discurso indirecto livre que me atravessa de um lado ao outro e que me vem doutros mundos ou de outros planetas" (Deleuze \& Guattari 2007: 119).

Impossibilitado no plano cinematográfico de "proceder à mimesis naturalista de qualquer linguagem, qualquer hipotético 'olhar' de outrem sobre a realidade" (Pasolini 1982: 146) (como sucede no plano literário), a operação do cineasta só pode ser estilística (mais precisamente, técnico-estilística), e já não linguística. Assim, a subjectiva indirecta livre implicaria a libertação das possibilidades expressivas sufocadas pela tradicional convenção narrativa e uma redescoberta das qualidades oníricas, bárbaras, irregulares, agressivas e visionárias dos meios técnicos do cinema (idem). Note-se que a subjectiva indirecta livre proposta por Pasolini se refere fundamentalmente às imagens, à visão das personagens, e não aos diálogos por estas encenadas.

Em suma, o autor propõe uma imanência da forma ao conteúdo, da personagem ao cineasta, assim, o cinema de poesia apresentar-se-ia, por um lado, através dessa subjectiva indirecta livre, na qual o realizador se serve de um "'estado de alma psiquicamente dominante do filme'” (idem: 149) e, por outro lado, através de um filme subterrâneo de carácter "inteira e livremente expressivo-expressionista" (idem) que se dá a ver por via dos planos e ritmos de montagem e que, de acordo com o autor, liberta a linguagem da sua função, expondo-a como "linguagem em si própria" (idem). As séries de "quadros" produzidos pela montagem, as variações de pontos de vista sobre uma mesma realidade, 0 zoom, os travellings, as paragens, em suma, esse desejo de "fazer sentir a câmara" constituem, para Pasolini, os procedimentos técnicos de um estilo, que afinal julgamos ter- 
se tornado numa tradição, instituída, portanto, no cinema moderno ocidental. ${ }^{9}$ Assim, para Pasolini, a personagem é expressa (a sua doença, a sua anomalia, a sua condição, etc.) através das técnicas estilísticas do autor-cineasta (movimentos de câmara, desvios, raccords, etc.).

Inúmeros traços deste cinema de poesia poderão ser encontrados nos filmes de António Reis e Margarida Cordeiro: Jaime (1974) apresenta-se como um filme esquizofrénico - corrupio de desenhos, sons, cores - sobre um pintor esquizofrénico, Jaime Fernandes, no qual o olhar do cineasta se confunde quase na totalidade com o olhar da personagem, cuja presença nunca surge de facto senão justamente através desta audiovisão trans-subjectiva dos riachos, das árvores, do vento, das batas brancas, do hospital psiquiátrico; em Trás-os-Montes (1976), como já vimos com Daney, o afastamento (cultural, social, geográfico, etc.) a que fora votada aquela comunidade [para estes desígnios, a personagem colectiva] expressa-se também através da câmara, dos procedimentos estilísticos, ao "chamar a atenção aquilo que no plano [...] remete para algures, assim construindo, pouco a pouco, aquilo a que poderíamos chamar o 'estado fílmico de uma província'” (Daney 1977). Se, no primeiro filme, a poesia resulta sobretudo de um trabalho de montagem, no segundo resulta do trabalho da imagem. Por sua vez, tais filmes enquadram-se respectivamente nas duas linhagens apresentadas por Rosa Maria Martelo em torno da relação entre a poesia moderna e o cinema, ambas ancoradas em figuras de estilo ou figuras expressivas: uma que se "funda na metonímia e diz respeito ao fluxo das imagens em relações de contiguidade, de choque, de tensão", que seria, portanto, uma poesia da montagem, e outra que vem "do estranhamento provocado pela imagem (em sentido retórico), na metáfora, na catacrese (aproximável da noção deleuziana de imagemcristal [...])", que seria uma poesia da imagem (Martelo 2012: 29-30). Por sua vez, a autora apresenta ainda "a possibilidade de articulação das duas vias" (Martelo 2012: 39), a mesma que julgamos poder encontrar-se no cinema de António Reis e Margarida Cordeiro.

Para retomar os termos de Pasolini e os procedimentos poéticos do cinema, o que Reis e Cordeiro parecem produzir, aos olhos de Daney, são estilemas e já não sintagmas de uma gramática estilística: 
É preciso levar a sério Reis quando, na conversa, ele fala de "tábua-rasa". E ele não tem a certeza de que esta atitude seja, finalmente, preferível àquela que consiste em trabalhar a partir do conhecimento ou do suposto conhecimento do espectador, quando não a partir de uma doxa comum (geradora, como qualquer doxa, de preguiça satisfeita, particularmente devastadora nas ficções de esquerda). (Daney 1977)

Em Ana (1982), o ritmo solene e elegíaco do filme, dos travellings pelas paisagens da serrania, dos gestos parcimoniais da amamentação de um recém-nascido, expressa a caminhada de Ana em vida e a sua condição, por fim, moribunda - com o recurso simbólico das barcas como meios de passagem - na qual o ciclo vital se dá a ver pela circularidade do elogio do quotidiano: as refeições, as caminhadas, os animais, as conversas (também na "poesia de António Reis, a morte pouco mais é do que uma diferença de grau" (Prado Coelho 1967). Como repara João Bénard da Costa, em Rosa de Areia (1989), o último filme da dupla, há um abandono das personagens em prol dos designados condutores, "relevos de um sonho, oueds temporários", porque se trata essencialmente de um "filme de matérias" (Cordeiro \& Reis 1989). ${ }^{10}$ Nesse sentido, será o mais poético filme da cinematografia de Reis e Cordeiro, na medida em que apenas o estilo garante a coesão do objecto fílmico; é, de facto, o único "protagonista do filme" (Pasolini 1982: 188-189).

Ainda na crítica de Rosa de Areia (1989), Bénard da Costa (1989) serve-se da terminologia da linguística na tentativa de "entender a prodigiosa construção do filme", de encontrar um sentido para o filme. Porém, conclui que "não há diferença de significação e de significado, entre um plano de segundos de uma seara ondulante, ou de um campo de flores às vezes pacificado, e uma sequência de quatro ou cinco minutos que narra uma história" (idem). ${ }^{11}$ António Reis e Margarida Cordeiro arrancam uma fala, um linguarejar singular, à linguagem do cinema. Escapam ao sistema gramatical e re-significam as imagens, os objectos, os planos, a cada momento, sem pré-determinações: "aquilo que o plano A mostrava e que o plano B escamoteou pode muito bem reaparecer no plano C, mas travestido, sem nenhuma prova de não ser transformado em algo de diferente" (Daney 1977). 0 erro de Bénard da Costa consiste justamente em tentar "entender a prodigiosa 
construção do filme", ou seja, extrair um sentido de Rosa de Areia (1989) e é aí que reside inevitavelmente a qualidade poética do próprio filme. Como nota Silvina Rodrigues Lopes:

o poema, rigorosamente, não quer dizer nada", porém, "não deixa de ser razoável figurar na 'voz do poema' [...] o seu modo singular de fazer sentido, isto é, a peculiar relação que ele instaura de cada vez que é lido. Com a condição de nunca reduzirmos 'sentido' a 'o sentido', pois o facto de dizermos que há sentido não supõe que esta seja uma unidade, algo fixo ou fixável, como é o significado ou o seu plural" - "a sua condição é a errância. (Lopes 2012: 76-77)

O cinema de Reis e Cordeiro surge como uma abertura, uma multiplicação, que recusa ser assimilada, expondo apenas a sua própria indecifrabilidade, "preservar-se como presença do não-revelado, do não-dito" (Lopes 2017: 20). Ainda de acordo com a autora, a ruptura seria qualidade intrínseca à poesia e, portanto, esta implicaria sempre um afastamento daquilo que a que se chama “'facilidade de comunicação'” (idem).

\section{0 estilo de uma vida}

Quer para Pasolini, quer para António Reis, o plano da produção estética rebate-se sempre sobre o plano da existência, e, portanto, da ética e também da política. Se a poesia é "uma forma de não gritar" (Prado Coelho 1967) e constitui em si uma forma de resistência anti-ideológica na medida em que "corresponde a um uso não-instrumental da linguagem" (Lopes 2017: 75) (recusando a dimensão constatativa da linguagem em detrimento da sua dimensão performativa), por sua vez, o cinema, ao longo da sua curta história, tem-se revelado como um meio privilegiado de instrumentalização ideológica, assentando sobretudo no modo como os filmes são realizados e nas escolhas técnico-estilísticas de que resultam. ${ }^{12}$ Ora, António Reis e Margarida Cordeiro pertencem a esse punhado de cineastas que resgatam a poesia por via do cinema porque lhe consagram uma permanente recusa da interpretação, da sua total compreensão, “o todo provável” (Lopes 2017: 77).

"Pintar é certamente para mim a única forma de vida, a única forma que tenho para defender-me da vida": estas são palavras do pintor Piero Guccione, citadas por Giorgio Agamben (2013: 361), na conclusão de uma conferência em torno da Arqueologia da Obra 
de Arte. No cerne de uma ontologia modal, proposta por Agamben, o conceito de forma-devida refere-se não àquilo que alguém é mas ao modo como é; “é uma 'maneira manancial', não um ser que tem essa ou aquela propriedade ou qualidade, mas um ser que é o seu modo de ser, que é o seu surgir e é continuamente gerado pela sua 'maneira' de ser" (Agamben 2017: 251). Ainda de acordo com o autor, toda a existência tentaria, pelo menos, fazer coincidir a vida que vivemos (vita quam vivimus) - ou seja, o conjunto de factos biográficos e a vida pela qual vivemos (vita que vivimus), aquilo que "torna a vida visível" (Agamben 2017: 253). Assim, na proposta agambeniana, a forma-de-vida corresponde a uma ontologia do estilo: "nomeia o modo como uma singularidade dá testemunho de si no ser, e o ser expressa a si em cada corpo" (Agamben 2017: 261). É justamente neste sentido que se poderia, então, evocar um estilo reisiano comum à poesia e ao cinema, a expressão de uma vida e de uma forma-de-vida que reencontramos na leitura dos poemas como no visionamento dos filmes.

Numa tal problematização da relação entre arte e vida, o conceito de forma-de-vida não seria definido "pela relação com uma práxis (energeia), nem com uma obra (ergon), mas por uma potência (dynamis) e por uma inoperosidade" (Agamben 2017: 276). Assim, tal forma-de-vida exigiria a contemplação de uma potência, ou seja, de uma abertura permanente da obra à possibilidade, a um novo uso possível, que se daria por via da sua inoperosidade, e que recusaria qualquer forma identitária pré-estabelecida: "verdadeiramente poética é a forma de vida que, na própria obra, contempla a própria potência de fazer e de não fazer e nela encontra paz" (Agamben 2017: 277). 


\section{NOTAS}

${ }^{1}$ Sendo Deleuze e Guattari uma das referências teóricas em que o presente artigo se ancora, parece-nos fundamentalmente notar a relevância atribuída pelos autores à utilização do artigo indefinido - como acontece neste poema de António Reis -, bem como a sua relação com outras noções como acontecimento, individuação e hecceidade: "vocês têm a individuação de um dia, de uma estação do ano, de um ano, de uma vida (independentemente da duração) - de um clima, de um vento, de um nevoeiro, de um enxame, de uma matilha (independentemente da regularidade). [...] É o próprio lobo, ou o cavalo, ou a criança que deixam de ser sujeitos para devir acontecimentos, nos agenciamentos que não se separam de uma hora, de uma estação, de uma atmosfera, de uma ária, de uma vida" (Deleuze \& Guattari 2007: 334). De resto, parece-nos que boa parte da teoria deleuziana - quer do cinema, da literatura, como da ontologia - poderá ajustar-se às propostas estéticas de António Reis e Margarida Cordeiro.

2 Sobre a dualidade singular e universal no cinema de António Reis e Margarida Cordeiro, Serge Daney afirmou, a propósito do filme Ana (1982), que "há muito tempo que um filme não nos lembrava com tanta evidência que o cinema é simultaneamente uma arte do singular e do universal [...]. E quando, em Ana, Reis lê - em off - um poema de Rilke sobre o plano do menino doente no seu sono agitado, não é um efeito decorativo, é essa ideia de poeta (António Reis escreveu poemas, foram publicados) de que há rimas neste mundo terreno. Aproximadas, abraçadas, entrelaçadas. E que o cinema é ainda bastante local (e não provinciano) e bastante universal (e não esperanto) para as poder deixar vir" [sublinhado nosso] (Daney 1983).

${ }^{3}$ Sobre as presenças cinemáticas na poesia portuguesa contemporânea, ver Martelo, Rosa Maria (2012), $O$ Cinema da Poesia, Lisboa, Documenta.

${ }^{4}$ Tais recortes ou intervalos implicam "a cooperação do leitor para completar ou preencher o que apenas é entremostrado ou sugerido" (Martinho in Reis 2017: 10).

${ }^{5}$ Para Bénard da Costa, o último filme da dupla marca o expoente radical de um cinema que não se funda nem nas personagens, nem em qualquer outro elemento da acção narrativa clássica, mas na lógica do imaginário dos autores: “[...] Rosa de Areia, ao contrário de Trás-os-Montes e de Ana, não tem um fio narrativo, pelo menos na acepção convencional do termo. Ténue era esse fio nos filmes anteriores, mas existia. [...] Os únicos guias no mundo deste filme, no tempo deste filme, são os autores, tão expostos quanto secretos para usar palavras deles. E expostos - mais expostos ainda do que nos filmes anteriores - porque a ordenação das imagens não obedece a outra lógica que não a do seu próprio imaginário, nunca tão assumido e tão fulgurante como aqui. [...] Tudo é imagem. Tudo é fragmento. Tudo é uno" (Bénard da Costa 1989).

${ }^{6}$ Embora Deleuze e Guattari se sirvam da terminologia pasoliniana na formulação teórica do discurso indirecto livre, os autores distanciam-se nas aproximações relativas à relação entre linguagem e vida. Por um lado, para a dupla, "a linguagem não é a vida, dá ordens à vida; a vida não fala, ouve e espera" (Deleuze \& Guattari 2007: 109-110); e, pelo contrário, para Pasolini a única linguagem que pode ser chamada linguagem 
"é a linguagem da realidade natural. Por exemplo, a linguagem de fieiras de álamos e dos prados verdes [...] (Pasolini 1982: 205).

7 Porém, contrariamente ao carácter instrumental da comunicação por palavras, a "comunicação cinematográfica é arbitrária e aberrante, sem precedentes instrumentais efectivos, dos quais todos sejam normalmente utentes" (Pasolini 1982: 137). Já para Gilles Deleuze, sendo a comunicação da ordem das palavras de ordem, da esfera do controlo, opõe-se ao movimento da criação artística ((Cf. Deleuze, Gilles, (1987), Qu'est-ce que l'acte de création?, conferência realizada na fundação Femis a 17 de Maio, <http://www.lepeuplequimanque.org/acte-de-creation-gilles-deleuze.html> (último acesso a 31/07/2019))

${ }^{8}$ Adopta-se aqui a noção de atmosfera como proposta por José Gil: uma atmosfera que procede por osmose (Gil 2002: 25), "poeira de pequenas percepções em que se penetra, com que se impregna, e que 'cola' como um fascínio" (ibidem). Sobre o conceito de atmosfera: "[...] A atmosfera já de si marca uma estranheza: entrar numa atmosfera é deslizar imperceptivelmente (ou bruscamente) para um outro "meio", que aparece primeiro como indeterminado - mais precisamente como uma espécie de vazio indeterminado sob fundo de familiaridade" (Gil 2002: 25).

${ }^{9}$ Como repara Pasolini, rapidamente as possibilidades infinitas desta linguagem sem dicionário cederam a uma institucionalização linguística: “[...] a breve história estilística do cinema, por causa da limitação expressiva imposta pela enormidade numérica dos destinatários do filme, obrigou a que os estilemas, que no cinema se tornaram de imediato sintagmas e que, portanto, reintegraram a institucionalidade linguística, fossem poucos e, sobretudo, grosseiros (lembremo-nos mais uma vez das rodas da locomotiva, a série infinita de primeiros planos idênticos etc.)" (Pasolini 1982: 142).

10 Os cineastas apresentam assim o filme, recorrendo a uma noção deleuziana: "Matérias em constante devir: o vento natural converte-se em vento de tuba, o vestido das actrizes contrasta com as nuvens, a tridimensionalidade cai aos pés da bidimensionalidade, o plano-sequência é emparedado pelo fixo, a música é o silêncio e a cor modulada, a luz mais pura passa a ser flutuante e difusa. 0 sentido do trabalho sobre as matérias (implicando-se e implicadas) não pode, portanto, delimitar-se: é múltiplo, refaz-se constantemente e sobretudo interroga, elabora formas..." [sublinhado nosso] (Cordeiro \& Reis 1989).

${ }^{11}$ Bénard da Costa (1989) recusa, no mesmo texto, a possibilidade de fazer encontrar a teoria pasoliniana e o cinema de Reis e Cordeiro, afirmando mesmo que: "não há cinema mais directo, menos subjectivo do que o cinema de Margarida Cordeiro e António Reis. Jamais os autores entram nas almas dos seus personagens (se existem personagens e se têm alma) adotando a sua psicologia ou a sua língua [...]”.

${ }^{12}$ A este respeito, cf. The Pervert's Guide to Ideology (2012), realizado por Sophie Fiennes e escrito por Slavoj Žižek.

N. 41 - 12/ 2019| 131-147 - ISSN 2183-2242 | http:/dx.doi.org/10.21747/21832242/litcomp41a6 


\section{Bibliografia}

Agamben, Giorgio (2013), "Arqueologia da Obra de Arte" in Princípios - Revista de Filosofia, tradução de Vinícius Honesko, 20 (34), Julho/Dezembro, Natal, pp. 349-361, doi: http://www.arquitecturadelastransferencias.net/images/artes-visuales/agambemArqueologia_da_Obra_de_Arte.pdf (acedido a 31/07/2019).

-- (2017), O Uso dos Corpos, tradução de Selvino J. Assman, São Paulo, Boitempo.

Araújo, Nelson (2016), Cinema Português - Interseções estéticas nas décadas de 60 a 80 do século XX, Lisboa, Edições 70.

Costa, João Bénard (1989), "O crepúsculo inicial ou a aurora final” in Foco - Revista de Cinema, <http://www.focorevistadecinema.com.br/FOC01/benard-rosa.htm $\geq$ (último acesso em 31/07/2019).

Celan, Paul (1996), Arte Poética - O Meridiano e outros textos (ed. orig. 1971), tradução de João Barrento e Vanessa Milheiro, Lisboa, Cotovia.

Cordeiro, Margarida/ António Reis (1989), “Rosa de Areia - Declaraciones”, publicado originalmente em Cinema, n. ${ }^{-}$16, Outono, $<$ http://elumiere.net/especiales/cordeiroreis/rosaareiadeclaraciones.php> (último acesso em 31/07/2019).

Daney, Serge (1983), "Au milieu du bout du monde", publicado originalmente em Libération a 8/6/1983, <http://antonioreis.blogspot.com/2004/11/055-ana-de-novo-nolibration.html $\geq$ (último acesso em 31/07/2019).

-- (1977), "Loin des lois", publicado originalmente em Cahiers du Cinéma, n. 276, Maio, pp. 42-44, <http://antonioreis.blogspot.com/2006/05/145-trs-os-montes-nos-cahiers-ducinma.html> (último acesso em 31/07/2019).

Deleuze, Gilles/ Félix Guattari (2003), Capitalismo e Esquizofrenia 2 - Mil Planaltos (ed. orig. 1980), Tradução de Rafael Godinho, Lisboa, Assírio \& Alvim. 
Gil, José (2002), "Ligação de inconscientes" in Crítica das Ligações na Era da Técnica, org. de José Bragança de Miranda e Maria Teresa Cruz, pp. 21-29, Lisboa, Tropismos.

Lopes, Silvina Rodrigues (2018), Literatura, Defesa do Atrito, Lisboa, Língua Morta.

Martelo, Rosa Maria (2012), O Cinema da Poesia, Lisboa, Documenta.

Molder, Maria Filomena (2018), "Vi as redes por dentro" in Como o sol, Como a noite, Org. Luís Lima, pp. 26-30, Porto, Porto/Post/Doc.

Pasolini, Pier Paolo (1982), Empirismo hereje [sic] (ed. orig. 1972), tradução de Miguel Serras Pereira, Lisboa, Assírio \& Alvim.

Coelho, Eduardo Prado (1967), “A Poesia de António Reis” in Poemas Quotidianos, Lisboa, Portugália, <http://antonioreis.blogspot.com/2005/09/098-poesia-de-antnio-reis-textode.html $\geq$ (último acesso em 31/07/2019).

Reis, António (2017), Poemas Quotidianos, Lisboa, Tinta-da-China.

Alexandra João Ramos Correia Martins é doutoranda em Estudos Artísticos - Arte e Mediações na Faculdade de Ciências Sociais e Humanas - Universidade Nova de Lisboa. Mestre em Estudos Artísticos pela Faculdade de Belas Artes da Universidade do Porto. Tem investigado em torno das relações entre cinema e filosofia. É programadora de cinema. 